\title{
Histological Changes in the Organs and Tissues of the Gobiid Fishes throughout their Life-span-VI Seasonal Changes in the Lymphopoietic Organs of the Flat-head Goby*1
}

\author{
Eimitsu TAMURA ${ }^{* 2}$ and Yoshiharu HonmA ${ }^{* 2}$ \\ (Received February 18, 1974)
}

\begin{abstract}
Lymphopoietic organs, such as the thymus, spleen and head kidney, of the two-year-old flat-head goby, Luciogobius guttatus, were examined histologically to elucidate the role and seasonal changes of these organs in relation to sexual maturity. The materials were collected at the gravel beaches of the Hayakawa River in the vicinity of Murakami City facing the Japan Sea throughout the year of 1972. The greatest enlargement in the parenchymatous tissue of the thymus and gonadal maturation of the present specimens occur one to two months earlier than in the specimens from Sado Island reported previously, i.e., the fish attained its spent condition by the middle of June. The cyclic pattern of the activity of the thymus was nearly identical with that of Sado Island specimens. The greatest number of small lymphocytes in the spleen, as well as in the lymphoid tissue of the head kidney, occur about one month later than in the thymus. The cyclic pattern of the changes in the size of interrenal cells is quite inverted to that of the changes in the number of small lymphocytes in the spleen and head kidney.
\end{abstract}

A rather distinct thymic activity in close relation to the annual cyclic change of the gonads has been demonstrated in every age group of the flat-head goby, although the involution gradually becomes heavier and heavier with increasing age." This phenomenon is in contrast to the regressive changes in the annual fish, such as the ice-goby and Ayu, ${ }^{2,3)}$ and in spawning Pacific salmon., ${ }^{4,5)}$ Apart from the age-involution, the correlation between the thymic hormone and other endocrine organs is obscure in fishes. In order to expand our knowledge concerning the lymphopoietic organs, the thymus, spleen and lymphoid tissue of the head kidney were examined histologically with special attention to the activities of interrenal tissue and gonadal development.

\section{Material and Methods}

A number of flat-head goby, Luciogobius guttatus GiLl were collected at monthly intervals throughout the year of March 1972 to January 1973 at the gravel beaches of the mouth of the Hayakawa River in the vicinity of Murakami City, Niigata Prefecture, facing the Japan Sea. One hundred and thirty specimens, $48-63 \mathrm{~mm}$ in standard length, were selected and employed for histological study. According to Dotsu's report, ${ }^{6}$ these specimens were estimated to be 2-year-old fish. The organs removed were fixed with

*1 Contributions from the Sado Marine Biological Station, Nigata University. This work was partly supported by a Grant-in-Aid for Fundamental Scientific Research from the Ministry of Education.

*2 Sado Marine Biological Station and Department of Biology, Faculty of Science, Niigata University, Niitata 950-21, Japan（田村栄光・本閒燨治：新潟大学理学部生物学教室） 
Bouin's and Bouin-Hollande-sublimate solutions on the spot, embedded in paraffin, cut serially 5 to $8 \mu$ thick, stained chiefly with hematoxylin-eosin and azan trichrome, and observed under the light microscope.

\section{Results}

As stated previously," the details of the seasonal changes in the gonads of this species will be given elsewhere. Gonadal development and sexual maturity of the present specimens occurred one to two months earlier than in the specimens caught at Sado Island, ${ }^{1}$ and the fish examined were all spent by the middle of June. Accordingly, although the mode and pattern of the seasonal change in the thickness of the parenchymatous tissue of the thymus are similar to those described in the previous paper, about one month's discrepancy is seen between them. As an index of the lymphopoiesis, the variation of the number of lymphocytes was counted in every specimen.

The thymus The thymus of the fish caught in late March was about $100 \mu$ in thickness and mitotic figures were encountered here and there. There were found a comparatively large number of lymphocytes ( $5 \mu$ in diameter), while small lymphocytes ( $3 \mu$ in diameter) were scarce (Fig. 1). Increase in the number of small lymphocytes was not so remarkable during late March to May. Toward the close of the spawning season, the middle of June, the thymus of the fish including spent fish reached a thickness of 180 $200 \mu$, and the increase in the number of small lymphocytes contained in the parenchyma was remarkable. They were calculated at a density of 53 cells $/ 625 \mu^{2}$ : this value corresponded roughly to three times the number in the specimens from the preceding month (May) (Fig. 2). Mitotic figures were frequently detected in this period. The thickness of the thymus became greatest in June to July (Textfig. 1). The vascular system containing connective tissue components of the basal region of the thymus developed considerably during July to August, while the parenchymatous tissue decreased to the thickness of $120 \mu$ accompanying the release of lymphocytes (Fig. 3). Some of the lymphoyctes scattered were found in the vascular tissue. In the middle of September, a decrease in the thickness of the parenchymatous tissue was great, about $80 \mu$, and regression of the vascular tissue occurred. Small lymphocytes were still encountered in a limited area (Fig. 4). After October, a distinct diminution of the gland and, in particular, a decrease in the number of small lymphocytes were seen, while, conversely, there was an accompanying increase in the amount of connective tissue elements in the basal region of the gland (Fig. 5). Thereafter, little by little, these regressive changes proceeded and reached the state seen in March.

The spleen In the spleen of the specimens caught from late March to the middle of April, the large $(6.0-7.0 \mu$ in diameter) and medium size $(3.5-4.8 \mu)$ lymphocytes were 


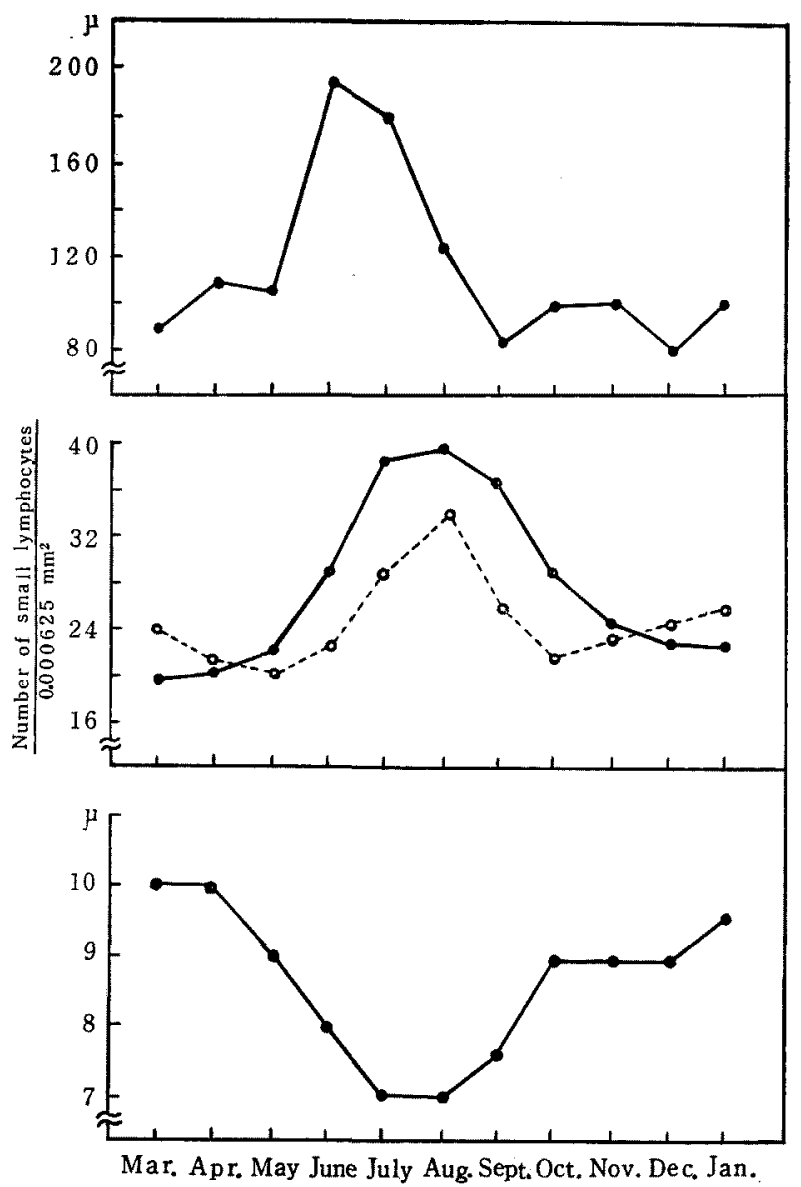

Textfig. 1. Seasonal changes in the depth of the thymus (top), the number of lymphocytes of head kidney (solid line, the middle) and of the periphery of splenic artery (dotted line, the middle), and the diameter of interrenal cell (bottom) in the flat-head goby caught in the mouth of the Hayakawa River near Niigata facing the Japan Sea.

concentrated chiefly around the splenic arteries (Fig. 6), but the number of small lymphocytes $(3.0 \mu)$ was very scarce and reached a density of $21-24$ cells $/ 625 \mu^{3}$. Next, toward the middle of June, the distribution of lymphocytes extended gradually from the splenic arteries to their surroundings. However, the mitotic figures were often encountered until this time (Fig. 7). In August, a decrease in the number of lymphocytes was seen, and the hemopoietic portion became pale (Fig. 8). Small masses of small lymphocytes scattered over the peripheries of hemopoietic portions, and a density of $29-34$ cells/625 $\mu^{2}$ was noted. The number of these small lymphocytes became greatest from July to August (Textfig. 1). After that, from September to October, the small lymphocytes were dispersed throughout the entire spleen, and decrease in the number of lymphocytes around the 
hemopoietic portion occurred. However, the recovery phase of the lymphocytes around this portion was detected again the next January corresponding to the picture seen in March as mentioned above.

The lymphoid tissue of the head kidney In the lymphoid tissue of the head kidney of a specimen caught in late March, a number of medium and large lymphocytes, 5.0-7.2 $\mu$ in diameter, were found, while the small lymphocytes, $3.0 \mu$ in diameter, were scanty and only a density of 15-17 cells/625 $\mu^{2}$ was found (Fig. 9). Toward the middle of May, the increase in the number of these small lymphocytes was not so remarkable. The density of small lymphocytes per unit area was 28 cells on an average in the middle of June, and the mitotic figures of the medium and large lymphocytes occurred frequently (Fig. 10). The number of lymphocytes became greatest in summer (July to August), about two times larger than in the specimens caught in spring (March to May) (Fig. 11). Development and distribution of the capillaries in the lymphoid tissue were also noticed in this season. After that, a decrease in the number of lymphocytes occurred gradually, 35 cells $/ 625 \mu^{2}$ in September, and 28 cells in October. Changes and cyclic patterns occurring in the spleen and head kidney were one month later than in the thymus (Textfig. 1).

The interrenal gland The interrenal gland of the flat-head goby is located along the cardinal vein approximately dorsally to the heart, and is independently far from the lymphoid head kidney. This feature is essentially similar to that of the ice-goby described previously ${ }^{2}$ (Fig. 12). The size of the interrenal cell in late March was comparatively large, ca. $10 \mu$, the nucleus, round in shape, measured $4.8 \mu$, and its cytoplasm had a number of small vacuoles (Fig. 13). These features appeared to indicate the hyperfunctioning state. Near the end of the spawning season (the middle of June), atrophy of the cytoplasm became conspicuous and the size of the cell decreased to $8 \mu$, while the size of the nucleus remained unchanged (Fig. 14). However, a slight decrease in the size of the nucleus was detected in the specimens caught in August, 3.6-4.0 $\mu$, and its contour was polyhedral. The diminution and atrophy of the cell $(7 \mu)$ and cytoplasm proceeded further in this month (Fig. 15). The recovery phase of the interrenal gland was encountered in the autumnal season (October to November), when the gonadal development became active again; the size of the interrenal cell became as large as $9 \mu$ (Fig. 16).

In brief, the greatest activity and concurrently hypertrophic figures of the interrenal cell were exhibited in the breeding season (June), and a heavy regression was brought about in summer (July to August) with a following recovery phase. These cyclic changes were quite in contrast and opposed to the changes in the number of small lymphocytes in the spleen and head kidney (Textfig. 1). 


\section{Discussion}

It is evident that the thymic hormones of the higher vertebrates exert an important role on the maturation of lymphoid cells and maintenance of immunologically competent cells which can respond to antigenic stimuli. Involution of the thymus gland occurring rapidly during the adolescent period has also been well known in mammals." Concerning the thymic activity in mature animals, ANDERSON ${ }^{8)}$ described the cyclic enlargement of the thymus during every molting period of the ring-necked pheasant (Phasianus colchinus). GALLETI and CANVALLARI ${ }^{9}$ ) reported the seasonal changes of the thymus of marmosets: the gland of hibernating animals during winter shows a conspicuous involution, and all the endocrine organs, especially the thymus, manifest a depressed condition. Therefore, during the hibernating period, the animal may undergo a periodical state of immunosuppression.

The diminution of the thymus occurring gradually with increasing age has been demonstrated in several species of fishes, although the commencement of involution differs among different species. ${ }^{2-4,10-13\}}$ A marked decrease in the number of lymphoid cells in the thymus, spleen and head kidney takes place in parallel with sexual maturation of the spawning Pacific salmon, ${ }^{4)}$ ice-goby" and Koayu. ${ }^{3)}$ Thymic involution of these fish may also suggest a great loss of immunity and a concurrent increase in the incidence of infection during and after the spawning season. On the other hand, in every age group of the flat-head goby a rather distinct thymic activity and lymphopoiesis in relation to the annual cyclic change of the gonads has already been reported by us, ${ }^{1 \prime}$ and the present examination also demonstrated almost the same results. These results show a possible relationship between the thymic activity and the gonadal and other endocrine activities occurring concurrently. It is of interest to find that the peak lymphopoiesis in the thymus takes place one month earlier than in the spleen and head kidney. Therefore, it would be expected that a thymic factor stimulates the lymphopoiesis in the other lymphoid tissues, although in the fish there are no secondary lymphanodules responding to thymic activity, such as are developed in the homoiothermal animals.

In her extensive work on the hormones and lymphoid systems of characinid, Astyanax mexicanus, RASQUIN ${ }^{141}$ reported that the ACTH injection caused slight or no activation of the thymus comparable to the control, while implantation of carp pituitary resulted in a sharp involution of the gland. However, the spleen and the lymphoid tissue of the head kidney were more sensitive to these stimuli than the thymus. Moreover, when the interrenal tissue was hypertrophied by pituitary injection, the thymus was involuted. A nearly identical situation was seen in the present examination of the flat-head goby. Therefore, it is suggested that the corticosteroids from the interrenal gland mediated and provoked by the hypophysial ACTH cells may suppress the lymphopoiesis of the thymus. 
It is not known whether the thymus has a possible role on the longevity of the spawning fish whose physiological condition is remarkably emaciated. Much more investigation is needed to demonstrate experimentally the interrelationship between the activities of lymphopoietic organs and the endocrines.

\section{References}

1) E. Tamura and Y. Honma: This Bull., 39, 1003-1011 (1973).

2) E. TAMURA and Y. HoNMA: ibid., 36, 661-669 (1970).

3) Y. Honma and E. TAMURA: ibid., 38, 995-1005 (1972).

4) O. H. RoberTson and B. C. WeXLER: Endocrin., 66, 222-239 (1960).

5) O. H. RoBertson and B. C. WeXIER: Gen. Comp. Endocrin., 2, 458-472 (1962).

6) Y. Dotsu: Sci. Bull. Fac. Sci., Kyushu Univ., 16, 93-100 (1957).

7) R. A. Good and A. E. Gabrielson: "The thymus in immunobiology" Hoeber Div. of Harper \& Row, N.Y. (1964).

8) W. L. Anderson: Condor, 72, 205-208 (1971).

9) G. Galleti and A. Canvallari: Acta anat., 83, 593-605 (1972).

10) F. Von HAGEN: Zool. Jahrb., 61, 467-538 (1936).

11) E. HAFTER: J. Morphol., 90, 555-582 (1952).

12) R. FäNGE: Gen. Comp. Endocrin, 9, 449-450 (1967).

13) W. Rizkalla: Acta Vetr. Acad. Sci. Hung., 19, 331-342 (1969).

14) P. Rasquin: J. exp. Zool., 117, 317-358 (1951). 
Plate 1.
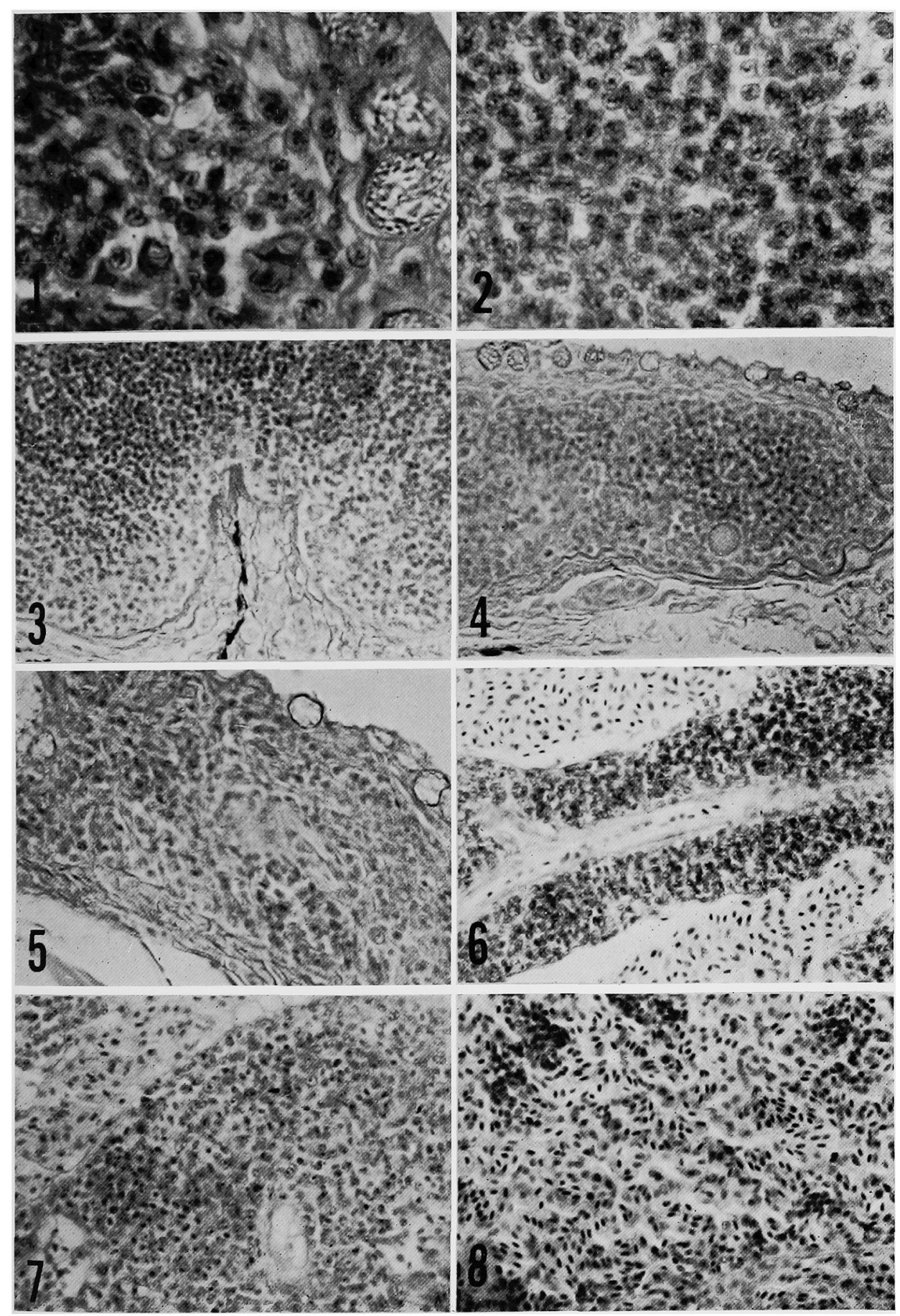
Plate 2.
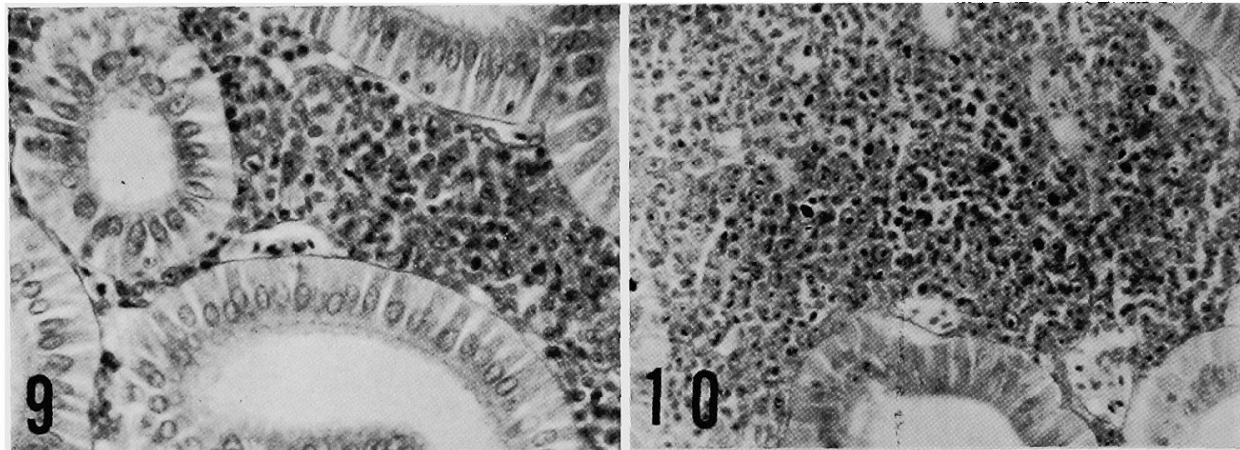

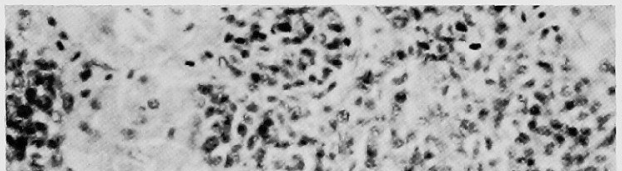

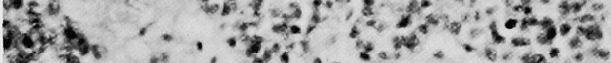

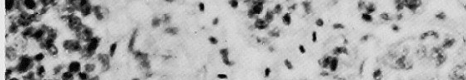

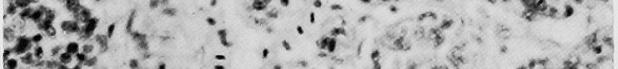

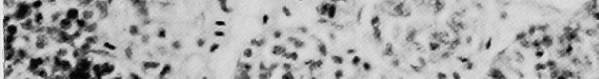

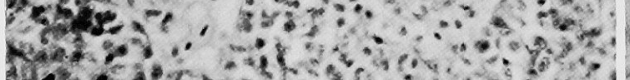

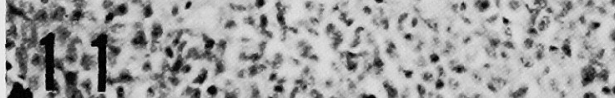
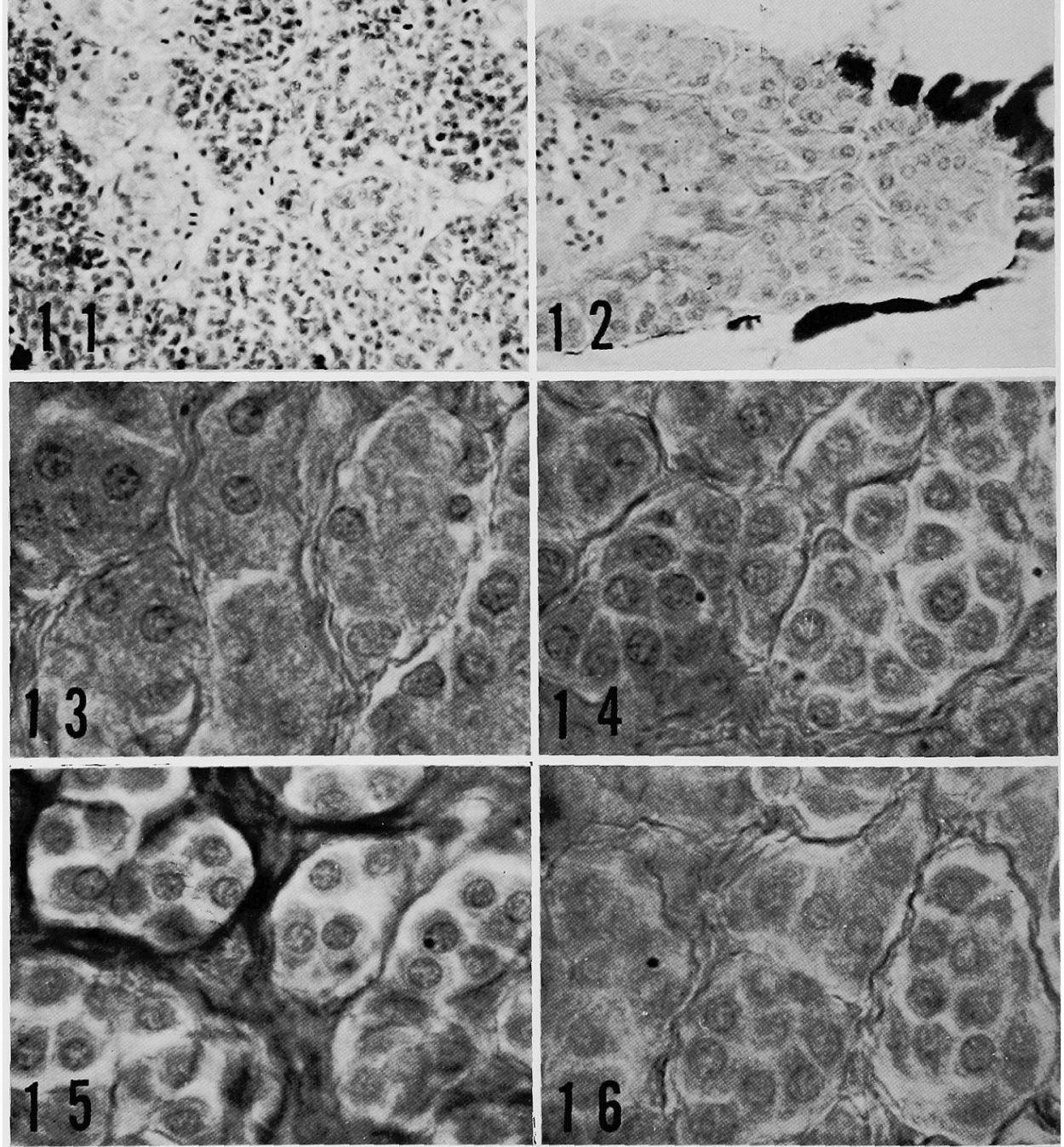


\section{Plate 1.}

Fig. 1. Section of the thymus of the flat-head goby caught in March showing a small number of small lymphocytes. $\times 1500$

Fig. 2. Thymus of a fish caught in June showing the parenchymatous tissue with densely packed small lymphocytes. $\times 1500$

Fig. 3. Thymus of a fish caught in August. In this specimen, a slight decrease in the thickness of the parenchyma and concurrently increase in the stromatous elements are seen. Decrease in the number of lymphocytes is also noticed. $\times 500$

Fig. 4. Thymus of a fish caught in September. Decrease in the thickness of the parenchymatous tissue is great, but a considerable number of lymphocytes still exist in a small part. $\times 500$

Fig. 5. Thymus of a fish caught in December. The density of lymphocytes in the parenchyma is very slight. $\times 500$

Fig. 6. Spleen of a fish caught in March showing a dense portion of the lymphocytes in the periphery of a splenic artery. $\times 500$

Fig. 7. Spleen of a fish caught in June showing a wide distribution of lymphocytes concentrated densely around the splenic arteries. Occassionally, mitotic figures are seen in this section. $\times 500$

Fig. 8. Spleen of a fish caught in August showing a decrease in the number of lymphocytes. Notice small masses of small lymphocytes. $\times 500$

\section{Plate 2.}

Fig. 9. Head kidney of a fish caught in late March showing a large number of large lymphocytes and a remarkably small number of small lymphocytes. $\times 500$

Fig. 10. Head kidney of a fish caught in the middle of June. A dense mass of lymphoid tissue and several mitotic figures of larger cells are noticed. $\times 500$

Fig. 11. Head kidney of a fish caught in August showing an increase in the number of small lymphocytes. $\times 500$

Fig. 12. The interrenal tissue of a fish caught in March showing the location of the gland. $\times 500$

Fig. 13. Interrenal tissue of a fish caught in late March showing a somewhat hypertrophic condition of the cells. Vacuoles in the cytoplasm are seen without difficulty. $\times 1500$

Fig. 14. Interrenal tissue of a fish caught in the middle of June showing a decrease in the amount of cytoplasm. $\times 1500$

Fig. 15. Interrenal tissue of a fish caught in August showing great diminution and atrophy of cytoplasm and nucleus of the cell. $\times 1500$

Fig. 16. Interrenal tissue of a fish caught in November showing the recovery phase of the cell condition. $\times 1500$ 